\title{
The Influence of the Frequency of the Internet Use on the Behavioral Relationship Model of the Mobile Device-Based Shopping
}

\author{
Shwu-Ing $\mathrm{Wu}^{1} \&$ Rou Jyun Chen ${ }^{1}$ \\ ${ }^{1}$ Department of Business Administration, National Chin-Yi University of Technology, Taiwan, Republic of \\ China \\ Corresponding: Shwu-Ing $\mathrm{Wu}$, Department of Business Administration, National Chin-Yi University of \\ Technology, No. 57, Section 2, Zhongshan Road, Taiping, Taichung, Taiwan, 411, R. O. C. E-mail: \\ wusi@ncut.edu.tw
}

Received: March 15, 2016

doi:10.5539/ijbm.v11n6p32
Accepted: April 6, 2016

Online Published: May 22, 2016

URL: http://dx.doi.org/10.5539/ijbm.v11n6p32

\begin{abstract}
In recent years, the increasingly innovative and diverse mobile devices have significantly promoted the mobile device-based shopping. What factors influence this kind of shopping? Will consumers purchase things with mobile devices? These are two topics that need to be explored. Through the literature analysis and the empirical research, this study aims to analyze the quality of information, system, service and mobile devices on the mobile device-based shopping platform. Moreover, it studies the attitude of consumers towards mobile device-based shopping, their willingness to adopt the shopping method and the behavioral relationship model in the actual mobile device-based shopping as well as compares the groups of different frequencies of the Internet use in terms of the relationship model.

With the convenient sampling, this study made an investigation among some of those who had experienced shopping on such mobile devices as tablets or smart phones. The 765 retrieved valid copies of questionnaire were divided into three groups - "often", "average" and "seldom" according to the frequency consumers undertook mobile device-based shopping and were then compared. The results showed that there were significant differences among the three groups in four relationship paths, including: 1) the information quality of the mobile device-based shopping platform has more significant positive influence on consumers' attitude path of mobile device-based shopping in the "average" group than in the other two; 2) the service quality of the mobile device-based shopping platform has more significant positive influence on consumers' attitude path of mobile device-based shopping in the "seldom" group than in the other two; 3) the preference for mobile device-based shopping has much significant positive influence on the behavior path of mobile device-based shopping in the "often" group. According to the research results, different groups have different behavior models. These results can serve as reference information in the decision-making of those who establish mobile device-based shopping platforms and manufacture mobile devices.
\end{abstract}

Keywords: mobile device, shopping behavior, information quality, system quality, service quality

\section{Introduction}

Mobile devices have become increasingly innovative and diverse in recent years. According to Cisco Visual Networking Index Global Mobile Data Traffic Forecast (2013), mobile devices would outnumber the global population in 2016. Gartner (2014) predicted that the number of personal computers would decline year by year whereas the number of mobile devices would climb. Schmidt (2014), the CEO of Google, said to the effect that it is an era of "Mobility comes first", and we will enter an era of "Mobility only" in the future, which indicated the advent of a golden age of mobile devices.

Mobile devices include smart phones and portable mobile devices. Defined as "ultra portable", portable mobile devices include tablets, laptops, mobile Internet devices, personal digital assistants (PDA), and portable game systems (Gartner, 2013). The advancement of mobile devices has changed the practice of consumption. According to the joint investigation of such mobile and Internet media as Millennial Media and comScore, the time consumers spent on mobile device-based shopping had surpassed that on personal computers, and $45 \%$ of consumers had replaced personal computer-based shopping with mobile device-based shopping. The "Survey on Mobile Shopping" released by the Market Intelligence \& Consulting Institute (MIC) (2013) showed that 57.1\% 
of mobile device owners adopted mobile device-based shopping in 2013, with an average consumption amount tantamount to that of personal computer-based shopping. It was obvious that the growth rate of mobile device-based shopping was higher than that of the entire online shopping market and that the popularity of mobile devices had significantly boosted mobile device-based shopping.

According to the MIC (2013), the factors that influenced consumers' preference for mobile device-based shopping were "a lower price than that of average online shopping" (55.6\%), "a more convenient shopping procedure" (33.2\%), and "more preferential" (29.5\%). The reasons why those who had mobile devices refused to adopt mobile device-based shopping were as follow: "inconvenient web page browsing" (57.0\%), "insecure transaction" (43.7\%), "unstable Internet access" (42.3\%), and "reluctance to reveal personal information" $(20.7 \%)$. What is required to persuade consumers to adopt such an innovative access platform for shopping? This is the topic that must be discussed.

In response to the trend in the electronic business market, Delone and Mclean (1992) put forward the first-generation information system success model, pointing out that information quality and system quality had great influence on online shopping. According to Keaveney (1995), enterprises would be able to enhance customer satisfaction, establish a relationship with customers, and keep their customers if they offered high-quality services. Delone and Mclean (2003) added two dimensions - service quality and net profit to convert the information system success model into the electronic business information system success model, and service quality also became an important dimension that influenced online shopping.

According to the Electronic Business Purple Paper released by Yahoo! Kimo (2014), consumers' adoption of mobile device-based shopping was also influenced by the quality of mobiles devices in addition to the Internet access. Therefore, the quality of mobile devices also has significant influence on mobile device-based shopping and should be taken into account.

According to what has been mentioned above, this study takes the three influencing dimensions (information quality, system quality and service quality) of the electronic business information system proposed by Delone and Mclean (2003) and the quality of mobile devices as independent variables and discusses if the four factors have significant influence on the attitude, intention and behavior of consumers towards mobile device-based shopping. Moreover, it analyzes the differences in the behavioral model of mobile device-based shopping among the groups of different frequencies of Internet use.

This study starts with the discussion on the collected literature and then analyzes the questionnaire to find out the influence of quality-related factors on mobile device-based shopping. Besides, it establishes the inter-dimension relationship model and compares the differences among the groups of different frequencies of Internet use. The subjects of sampling are consumers aging 20 or more in Taiwan.

\section{Literature Review}

\subsection{Type of Mobile Devices}

Mobile devices refer to the devices that can be linked to mobile services (Gong \& Tarasewich, 2004). A mobile device has three features, namely, "mobile", "handheld" and "wireless" (Seppälä \& Alamaki, 2003).

With the advancement of electronic communication and the Internet, there have been many kinds of mobile devices. According to Gong and Tarasewich (2004), mobile devices included wireless phones, PDA, and wireless handheld devices. The International Data Center (IDC) called mobile devices as converged handheld devices and divided them into two types: one was the voice-based smart phone which evolved from the combination of mobile phone and the PDA; the other was the data-based phone which derived from the integration of the PDA and the mobile communication technology and was also called the PDA. Caverly (2003) believed that mobile devices could be divided into laptop, the PDA + Wireless phone, the portable hard disc drive, and the personal digital assistant. According to the international research and consulting institution Gartner, mobile devices could be classified into smart phone and ultra mobile, and ultra mobile was defined as "ultra portable" which included tablets, laptops, mobile Internet devices, the PDA, and portable game systems.

According to the Research, Development and Evaluation Commission, Executive Yuan (2012), mobile device was defined as a device which could be operated through touch-control plane, featured mobility and wireless Internet access, and allowed users to download, install and apply software on the Internet; most of mobile devices were smart phones and tablets. Nowadays, the mobile devices that are widely used by average consumers are also smart phones and tablets. Hence, this study chooses "smart phone" and "tablet" as the research subjects according to the above-mentioned definitions and the currently widely-used devices. 


\subsection{Mobile Device-Based Shopping}

The proportion of the Taiwanese online shoppers who visited shopping websites and platforms in 2014 was $44.6 \%$ (Kimo, 2014), which meant that nearly one out of two online shoppers in Taiwan adopt mobile device-based shopping. The report also mentioned the frequency of mobile device-based shopping: $25 \%$ of online shoppers undertook it once a month, and $45 \%$ for more than once. Meanwhile, over 30\% of mobile device-based shoppers had no restriction on the amount of shopping. According to the MIC (2013), the time consumers spent on shopping websites and platforms every day was over half an hour, and they were dependent on mobile device-based shopping platforms. The investigation also demonstrated that the popularity of mobile devices had driven mobile device-based shopping and that there was a relationship between the growth of mobile device-based shopping and the increasing number of business opportunities.

The notion of mobile device-based shopping is gaining popularity, but what is required to persuade consumers to use such an innovative access platform for shopping? A successful mobile device-based shopping platform consisted of an excellent design of user interface, highly personalized functions, and the services featuring seamless integration of online and offline accesses, all of which were valued by consumers (Kimo, 2014). For that reason, more attention needs to be paid to quality-related factors in enhancing consumers' preference for mobile device-based shopping.

\subsection{Quality-Related Factors of Mobile Device-Based Shopping Platforms}

In face of the trend of electronic business, Delone and Mclean (1992) put forward the information system success model and deduced six dimensions to measure the success of an information model, including system quality, information quality, user satisfaction, the frequency of system use, and the impact of the system on individuals and organizations.

With the economic stability, the market has converted from the originally production-oriented one into the service-oriented one. Enterprises would be able to enhance customer satisfaction and forge a long-term relationship with customers if they offer high-quality services (Badlani, Motwani, \& Paryani, 2014). Pitt, Watson, and Kavan (1995) thought that services were expected by the users of the information systems in addition to hardware equipment; therefore, Delone and Mclean (2003) added two dimensions - service quality and net profit to convert the information system success model into the electronic business information system success model. This study focuses on mobile device-based shopping which is in the scope of electronic business, so the model is taken as the foundation of the conceptual architecture.

The electronic business information system success model proposed by Delone and Mclean (2003) comprises six dimensions, including information quality, system quality, service quality, the willingness of use, user satisfaction, and net profit. In this study, three variables of the model are used as the dimensions to measure quality-related factors, including system quality, information quality, and service quality.

\subsection{Quality-Related Factors of Mobile Devices}

According to the MIC (2013), 42.3\% of the consumers who had mobile devices did not adopt mobile device-based shopping because of unstable Internet access. However, the stability of Internet access is dependent on the quality of mobile devices; hence, it is obvious that the quality of mobile devices plays an essential role in mobile device-based shopping and is also an important variable.

The innovation of mobile devices influences the mobile device-based shopping of consumers. For instance, the $4 \mathrm{G}$ Internet features a wider coverage, a faster access, more information, so users prefer to it in terms of mobile services. For another, the Apple Company has launched Apple Pay which is characterized with fast payment and confirmation of users, so the owners of Apple mobile devices prefer to the mobile devices for shopping.

As far as the indicators of measuring the quality of products, Garvin (1987) put forward eight dimensions, including performance, features, reliability, conformance, durability, serviceability, aesthetics, and perceived quality. Consumers are deeply affected by others' views in the purchase of new products or services (Brown \& Reingen, 1987), so prestige is also a standard of measuring the quality of products. In terms of the measurement of product quality, Brucks and Zeithaml (1991) proposed six dimensions, such as performance, ease of use, functionality, durability, serviceability, and prestige.

This study adopts the dimensions proposed by Brucks and Zeithaml (1991), namely, performance, ease of use, functionality, durability, serviceability, and prestige, in the measurement of the quality of mobile devices.

\subsection{Consumers' Attitudes towards Mobile Device-Based Shopping}

Attitude is often regarded as an indicator predicting actual shopping (Assael \& Henry, 1998); it is a process of 
learning after which one would develop emotional or evaluative response to objects or consistent affection or abomination for things (Fishbein \& Ajzen, 1980).

Rosenberg and Hanland (1960) pointed out that attitude consisted of cognitive component, affective component and conative component. Cognitive component referred to personal faith in some things according to one's knowledge, concept, thought, and learning; affective component indicated personal subjective affection or abomination for things; conative component meant the willingness to purchase things according to personal faith or feeling. Assael (1992) believed that attitude comprised of product faith, product evaluation, and preference: product faith referred to the features some product had in the eye of consumers; product evaluation indicated consumers' affection and abomination for some product; preference was the tendency of buying.

According to Assael (1992), this study measures consumers' attitude towards mobile device-based shopping in three aspects-faith, evaluation and preference.

\subsection{Consumers' Willingness to Adopt Mobile Device-Based Shopping}

Willingness to buy refers to personal plan and tendency of buying a product (Spears \& Singh, 2004). It is often used to predict the behavior of buying (Cannière, Pelsmacker, \& Geuens, 2009); a stronger willingness to buy indicates a higher probability of buying and shows that consumers with positive willingness to buy will make positive commitment (Schiffman \& Kanuk, 2004).

Zeithaml, Parasuraman, and Berry (1996) divided consumers' willingness to buy into two types - positive and negative. A consumer with positive willingness to buy may praise and show preference for the company, increase the products to be bought, and strengthen his/her relationship with the company; on the contrary, a consumer with negative willingness to buy would reduce the number of the products he/she would buy from the company or choose other companies. Boulding, Kalra, Staelin, and Zeithaml (1993) put forward the argument on willingness to buy and divided into two types - "willingness to repurchase" and "willingness to recommend".

This study concentrates on consumers' willingness of adopting mobile device-based shopping, so "willingness to repurchase" and "willingness to recommend" are taken as the indicators of measurement.

\subsection{Consumers' Actual Adoption of Mobile Device-Based Shopping}

Actual shopping is the process where consumers put his ideas into practice, make efforts and obtains what they want (Engel, Blackwell, \& Miniard, 1990); it also refers to the actions consumers take to satisfy needs, including seeking, commenting and practicing (Schiffman \& Lesile, 1991).

No matter actual or Internet transaction, actual shopping is influenced by the frequency and instability of transaction and the exclusiveness of assets (Williamson, 1979). According to Covaleski (1997), all product publicity activities were designed for the actual shopping of consumers and aimed to increase consumers' frequency of transaction and the number of the products they buy. Therefore, this study measures consumers' actual adoption of mobile device-based shopping according to the frequency of transaction and the quantity of products to be bought, two factors proposed by Covaleski (1997).

\subsection{Frequency of Internet Use}

According to the AdReaction (2014) released by Millward Brown, Taiwanese led the world in terms of the time spent on surfing on mobile devices; normally, each Taiwanese spent at least 197 minutes (about 3.3 hours) on the Internet a day, and most of the time they focused on food. The investigation (2014) by the Ministry of Education showed that students spent 0-2 hours on the Internet a day, and those with frequent use of the Internet spend at least 4 hours. According to this, the frequency of Internet use can be classified into "no more than 2 hours" (seldom), "2 to 4 hours" (average), and "at least 4 hours" (frequent).

Taiwan Network Information Center (TWNIC) (2014) also found that most of the frequent Internet users were female ones aging from 25 to 34 who engaged in education and service, with a master's degree and a monthly income of NTD 30,001 to 40,000. Such consumers paid more attention to efficiency, the convenience of shopping and the product diversity on shopping platforms and had rich experience in online shopping. Most of the average Internet users had a high educational level and often used the Internet to seek information and handle practical office tasks. Those who seldom used the Internet were those who were old and had a lower educational level, and the reason for their seldom use of the Internet resided in their inability to use Internet-based products. The average time the frequent Internet users spent on online shopping was 76.23 days (about 2.3 months), with an average monthly amount of NTD 2,349.02 for online shopping, and all the indicators of the frequent Internet users were higher than that of the average and seldom Internet users. It also showed that there were differences in the behaviors of online shopping among the groups of different frequencies of Internet use. This is a topic 
worthy of discussion.

\section{Research Hypotheses}

3.1 The Influence of the Quality-Related Factors on Mobile Device-Based Shopping Platforms on Consumers' Attitude towards Mobile Device-Based Shopping

Access platform suppliers can enhance consumers' positive attitude towards access platforms if they provide an information system featuring complete information quality and system quality (D'Ambra \& Rice, 2001; Shih, 2004). Attitude is influenced by cognitive ease of use and cognitive usability (Davis, Bagozzi, \& Warshaw, 1989), so information quality and system quality would have significant positive influence on consumers' attitude towards mobile device-based shopping. Besides, Parasuraman, Zeithaml, and Berry (1985) thought that consumers' cognition of service quality stemmed from the gap between expectation and reality and that service quality would influence consumers' attitude; hence, service quality was in positive correlation with attitude (Angelova \& Zekiri, 2011). According to the above-mentioned arguments, the researcher makes three hypotheses:

H1: "Information quality" of mobile device-based shopping platforms would have significant positive influence on consumers' attitude towards mobile device-based shopping.

H2: "System quality" of mobile device-based shopping platforms would have significant positive influence on consumers' attitude towards mobile device-based shopping.

H3: "Service quality" of mobile device-based shopping platforms would have significant positive influence on consumers' attitude towards mobile device-based shopping.

3.2 The Influence of the Quality of Mobile Devices on Consumers' Attitude towards Mobile Device-Based Shopping

According to Ericsson Consumer Lab (2014), consumers would use mobile devices for such services as instant messaging, shopping, social media and watching movies; $26 \%$ of consumers said that their attitude towards service was influenced by service quality. Service quality, however, depended on the quality of mobile devices; therefore, high-quality mobile devices would enhance consumers' preference for mobile device-based shopping.

According to the "Investigation into Consumers' Attitude towards Apple Pay" released by the Lab42 (2014), over a half of the respondents said that the high-quality mobile devices provided by the Apply Company, including the more stable Internet access and the Apple Pay, would enhance consumers' willingness to adopt mobile device-based shopping. Therefore, high-quality mobile devices would strengthen consumers' positive attitude towards mobile device-based shopping and enhance their willingness to adopt mobile device-based shopping. According to what has been mentioned above, this study makes the following hypothesis:

H4: The quality of mobile devices would have significant positive influence on consumers' attitude towards mobile device-based shopping

3.3 The Influence of Consumers' Attitude towards and Willingness to Adopt Mobile Device-Based Shopping and Their Actual Use of Mobile Device-based Shopping

Fishbein and Ajzen (1980) believed that the personal actions based on collected information and systematic and rational thinking were a part of the Theory of Reasoned Action (TRA). Afterwards, Ajzen (1985) found that behavioral willingness was influenced by the behavioral attitude, subjective rules, and cognitive behavior. To strengthen the prediction ability of the TRA, Ajzen (1985) extended the TRA into the Theory of Planned Behavior (TPB) which indicated that personal attitude towards things would influence behavioral willingness and then actual behavior.

Dzewaltowski, Noble, and Shaw (1990) compared the Theory of Social Cognition, the TRA and the TPB and found that the TPB could give a more accurate prediction of actual behavior and was more suitable for describing people's behavior in the use of information technology products (Ajzen, 1985). According to what has been mentioned above, this study makes the following hypotheses:

H5: Consumers' attitude towards mobile device-based shopping could have significant positive influence on consumers' willingness to adopt mobile device-based shopping

H6: Consumers' willingness to adopt mobile device-based shopping could have significant positive influence on consumers' actual mobile device-based shopping 


\subsection{The Influence of the Frequency of Internet Use on the Relationship Model of Mobile Device-Based Shopping}

Darian (1987) noticed that the male surpassed the female in the frequency of Internet use and showed relatively stronger acceptance. According to Robertson, Zielinski and Ward (1984), those with a high income and a high-level education were more willing to accept complicated Internet access and thus were more intended to adopt online shopping.

According to the investigation by the TWNIC (2014), there were significant differences in gender, age, educational level, monthly income, occupation and the time of Internet use among the groups of different frequencies of Internet use. Moreover, differences were also detected in online shopping, such as the cycle of online shopping and the average amount of online shopping.

This study analyzes the differences in the behavioral model of the mobile device-based shopping of groups of different frequencies of Internet use and thus makes the following hypothesis:

H7: There is significant difference on the path and strength of the relationship model of mobile device-based shopping among the groups of different frequencies of Internet use

\section{Research Design}

\subsection{Research Framework}

The research framework of this study (see Figure 1) is to discuss the influence of quality-related factors (the information quality, system quality and service quality of mobile device-based shopping platforms and the quality of mobile devices) on consumers' attitude towards and willingness to adopt mobile device-based shopping and their actual mobile device-based shopping. Meanwhile, it aims to analyze the influence of the groups of different frequencies of Internet use on the path and relationship of the behavioral model of mobile device-based shopping.

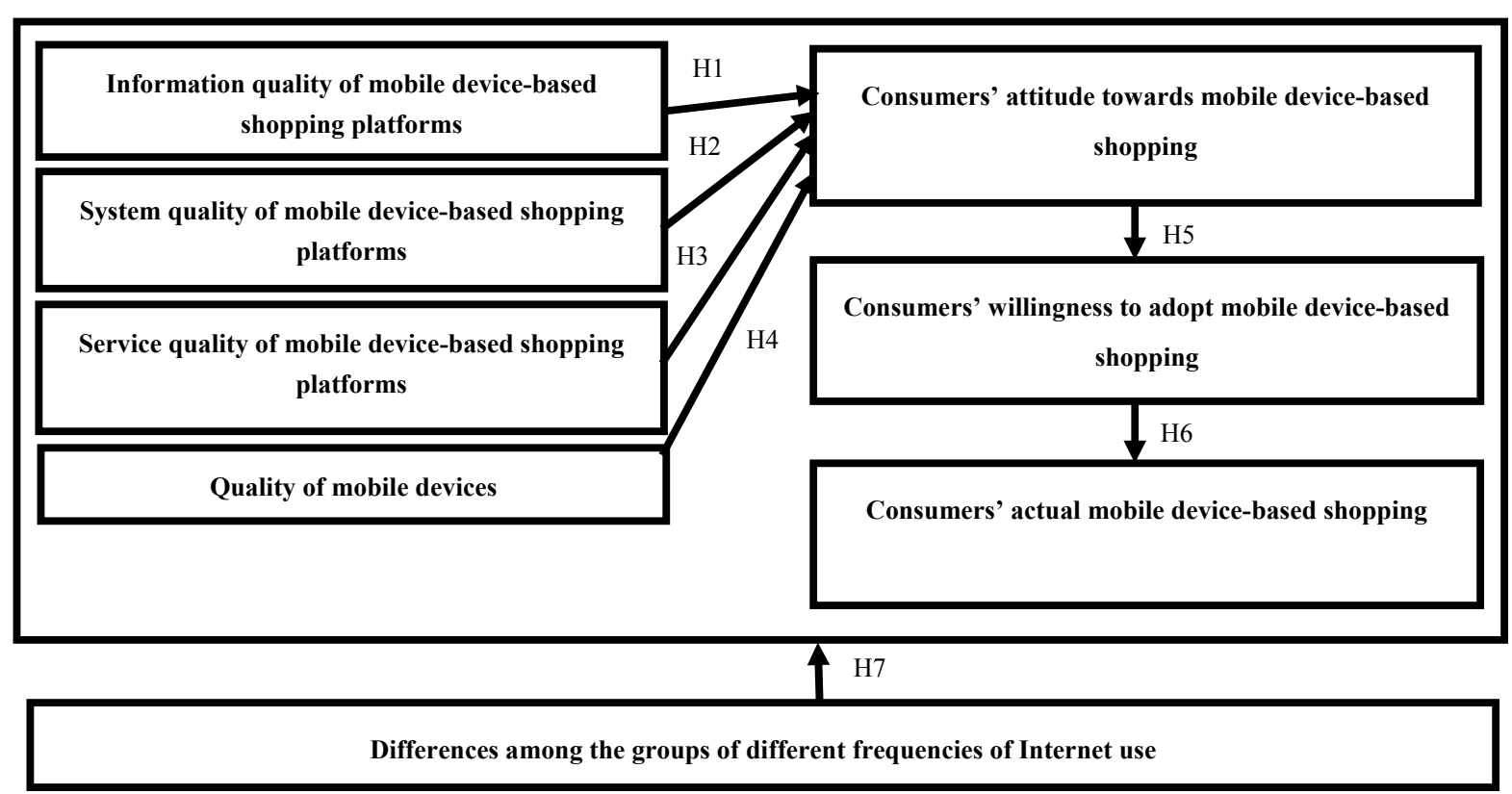

Figure 1. Research framework

\subsection{Pretest and Pilot of Research Variables}

First and foremost, this study collected relevant theories and literature as the basis of the research architecture. Then, it adopted a questionnaire investigation for demonstration to find out the influence of quality-related factors on the behavior of mobile device-based shopping. To obtain valid questionnaire, this study improved the questionnaire through pretest and pilot test before the distribution of the copies. In the pretest, the convenient sampling was applied to select 30 consumers who tried adopting or were adopting mobile device-based shopping for an in-depth interview. The result showed that some question items were not clearly stated, so these problematic sentences were modified and some examples were added for clarification. After the modification, the convenient sampling was used again to select 100 respondents as the sample of the pilot test, and the 
reliability and validity of the retrieved questionnaire copies were analyzed.

According to the results of the pilot, the value of Cronbach's $\alpha$ of all dimensions for measurement stayed between 0.861 and 0.928 , which met the standard of over 0.7 . The correlation coefficient between sub-items and total items was over 0.5 , which meant that all dimensions had high reliability (Nunnally, 1978). The factor analysis manifested that the feature values of all dimensions were over 0.1 , and the cumulative explained variation was higher than 0.5 ; the factor load of all variables were higher than 0.5 , which indicated that all dimensions had the validity of convergence (Kerlinger, 1978; Kaiser, 1958). For all these reasons, the questionnaire was taken as an official one.

The official questionnaire consists of eight parts, namely, the information quality of mobile device-based shopping platforms, the system quality of mobile device-based shopping platforms, the service quality of mobile device-based shopping platforms, the quality of mobile devices, consumers' attitude towards mobile device-based shopping, consumers' willingness to adopt mobile device-based shopping, consumers' actual mobile device-based shopping, and basic information. For the first seven parts, the Likert's seven-point scale is adopted, ranging from "Strongly disagree" to "Strongly agree" (from "1" point to "7" points); for the eighth part, nominal measurements were adopted.

\section{Research Results}

\subsection{Sample Structure}

In this study, those who used tablets or smart phones for mobile device-based shopping were taken as the research subjects, and the convenient sampling was applied to distribute the 800 copies of questionnaire. In the analysis, 35 invalid copies were discarded whereas 765 copies were kept, with a retrieval rate of valid copies of $95.6 \%$. According to the analysis of sample distribution, female respondents occupied a larger proportion $(51.0 \%)$; the age group of 30-39 accounted for the largest proportion (32.2\%), followed by the one of 50-59 (22.0\%); those from central Taiwan took up the largest proportion (37.6\%), followed by those from northern Taiwan (32.8\%); those with a college education (junior college education) occupied the largest proportion (59.2\%), followed by those with a high school education (vocational education) (30.1\%); those engaging in the service industry accounted for the largest proportion (34.2\%), followed by students (14.1\%); those with an average monthly income of or a disposable income of NTD 10,001-30,000 took up the largest proportion (34.5\%), followed by those with an average monthly income of or a disposable income of NTD 30,001-50,000 $(31.8 \%)$; in terms of the time of Internet use, those with at least 4 hours occupied the largest proportion (37.3\%), followed by those with 1-2 hours (20.5\%); in respect of the most frequently-used mobile device, those choosing smart phones accounted for $81.2 \%$ and those choosing tablets $18.8 \%$; those who used mobile device-based shopping platforms once a month took up $36.5 \%$ (the largest proportion), followed by those with 2-3 times a month (34.1\%); in term of the amount of money spent in each mobile device-based shopping, those spending NTD 501-1,000 accounted for 34.5\% (the largest proportion), followed by those spending NTD 500 or less (20.9\%).

\subsection{The Reliability and Validity Analysis of the Official Questionnaire}

After the official questionnaire investigation, this study made an analysis of the reliability and validity of all measurement dimensions to ensure the reliability of the questionnaire. In this study, the value of Cronbach's $\alpha$ and the factor analysis were adopted to evaluate the reliability and validity of the questionnaire. According to Nunnally (1978), if the value of Cronbach's $\alpha$ was higher than 0.7, the internal consistency of a questionnaire was high enough to be called a highly reliable questionnaire; according to Kerlinger (1978), the item to total correlation coefficient needed to be higher than 0.5. The result showed that the value of Cronbach's $\alpha$ of all dimensions and the correlation coefficient all met the standards, so the entire reliability of the questionnaire in this study is high (see Table 1).

In terms of validity, the factor analysis was applied to test the convergence validity of the questionnaire. According to Kaiser (1958), the eigenvalue of extracted factors must be higher than 1; the factor load of all variables in all factor dimensions must exceed 0.5 ; the cumulative explained variation was over 0.5 . The result showed that the values of all dimensions were higher than the standards, so the convergence validity of the questionnaire of this study was also high (see Table 1).

Additionally, this study evaluated the reliability and validity of the questionnaire according to the composite reliability (CR) and average variation extraction (AVE) of potential variables. The principle was that the CR value must be over 0.6 and the AVE value must be over 0.5 (Fornell \& Larcker, 1981). According to the result, the CR of all dimensions and factors stayed between 0.8988 and 0.943 , which was higher than 0.6. This 
indicated that the dimensions of this study had high internal consistency. Meanwhile, the AVE of the potential variables ranged from 0.5273 to 0.8054 , which was higher than 0.5 . This meant that all the measurement items in the factor dimensions were highly consistent (see Table 1).

Besides, this study followed the suggestion of Gaski and Nevin (1985) by making a relevance analysis to evaluate the differential validity among dimensions of the questionnaire, with the principle that the correlation coefficient of any two dimensions should be lower than the value of Cronbach's $\alpha$ of any dimension. Meanwhile, the square root of the AVE of all variables must be higher than the corresponding correlation coefficient between any two phases (Fornell \& Larcker, 1981). The result showed that all the correlation coefficients among the dimensions of this study satisfied the above standards; therefore, there was differential validity among the dimensions of the questionnaire.

Table 1. Analysis of the reliability and validity of the official questionnaire

\begin{tabular}{|c|c|c|c|c|c|c|c|c|}
\hline Factor & Mean & $\begin{array}{l}\text { Item-to-total } \\
\text { correlation } \\
\text { coefficient }\end{array}$ & $\begin{array}{l}\text { Factor } \\
\text { loading }\end{array}$ & Eigenvalue & $\begin{array}{l}\text { cumulative } \\
\text { explained } \\
\text { variation } \%\end{array}$ & $\begin{array}{l}\text { Cronbach } \\
\alpha \\
\text { value }\end{array}$ & $\begin{array}{l}\text { Component } \\
\text { reliability } \\
(\mathrm{CR})\end{array}$ & $\begin{array}{l}\text { Average } \\
\text { variance } \\
\text { extracted } \\
\text { (AVE) }\end{array}$ \\
\hline \multicolumn{9}{|c|}{ Information quality of mobile device-based shopping platforms } \\
\hline $\begin{array}{l}\text { Possess complete } \\
\text { commodities and } \\
\text { information }\end{array}$ & 5.4405 & .640 & .743 & & & & & \\
\hline $\begin{array}{l}\text { Frequently updated } \\
\text { commodities and } \\
\text { information }\end{array}$ & 5.6536 & .577 & .701 & & & & & \\
\hline Easy to understand & 5.6261 & .665 & .771 & & & & & \\
\hline $\begin{array}{l}\text { Web page and } \\
\text { interface are easy to } \\
\text { operate }\end{array}$ & 5.5725 & .663 & .767 & 4.218 & 52.722 & .871 & 0.8988 & 0.5273 \\
\hline $\begin{array}{l}\text { Provide many } \\
\text { additional functions }\end{array}$ & 5.6523 & .641 & .745 & & & & & \\
\hline Exclusive & 5.4000 & 611 & .711 & & & & & \\
\hline $\begin{array}{l}\text { Effective selection } \\
\text { and classification }\end{array}$ & 5.4601 & .675 & .756 & & & & & \\
\hline Protect users & 4.9464 & .500 & .600 & & & & & \\
\hline \multicolumn{9}{|c|}{ System quality of mobile device-based shopping platforms } \\
\hline $\begin{array}{l}\text { The system is } \\
\text { highly operable }\end{array}$ & 5.5203 & .652 & .763 & & & & & \\
\hline Always connected & 4.8797 & .662 & .766 & & & & & \\
\hline $\begin{array}{l}\text { The system is easy } \\
\text { to use }\end{array}$ & 5.3412 & .775 & .857 & 3.858 & 64.294 & .888 & 0.9153 & 0.6434 \\
\hline Correctly & 5.2614 & .749 & .835 & & & & & \\
\hline The response is fast & 5.1987 & .717 & .810 & & & & & \\
\hline Easy to use & 5.5961 & .668 & .777 & & & & & \\
\hline \multicolumn{9}{|c|}{ Service quality of mobile device-based shopping platforms } \\
\hline Efficient & 5.4105 & 671 & .769 & & & & & \\
\hline Service item & 5.3935 & .659 & .761 & & & & & \\
\hline Easy & 5.4863 & .631 & .733 & & & & & \\
\hline Highly safe & 4.6170 & .724 & .801 & & & & & \\
\hline $\begin{array}{l}\text { Respond } \\
\text { problems }\end{array}$ & 5.1660 & .770 & .842 & 4.329 & 61.839 & .897 & 0.9189 & 0.6184 \\
\hline $\begin{array}{l}\text { Compensation } \\
\text { channel }\end{array}$ & 4.9229 & .733 & .805 & & & & & \\
\hline $\begin{array}{l}\text { Adequate number } \\
\text { of connection } \\
\text { channels }\end{array}$ & 5.3490 & .706 & .789 & & & & & \\
\hline
\end{tabular}




\begin{tabular}{|c|c|c|c|c|c|c|c|c|}
\hline Factor & Mean & $\begin{array}{l}\text { Item-to-total } \\
\text { correlation } \\
\text { coefficient }\end{array}$ & $\begin{array}{l}\text { Factor } \\
\text { loading }\end{array}$ & Eigenvalue & $\begin{array}{l}\text { cumulative } \\
\text { explained } \\
\text { variation } \%\end{array}$ & $\begin{array}{l}\text { Cronbach } \\
\alpha \\
\text { value }\end{array}$ & $\begin{array}{l}\text { Component } \\
\text { reliability } \\
(\mathrm{CR})\end{array}$ & $\begin{array}{l}\text { Average } \\
\text { variance } \\
\text { extracted } \\
\text { (AVE) }\end{array}$ \\
\hline \multicolumn{9}{|c|}{ Quality of mobile devices } \\
\hline Effective & 5.7739 & .734 & .807 & \multirow{8}{*}{4.789} & \multirow{8}{*}{59.857} & \multirow{8}{*}{.904} & \multirow{8}{*}{0.9224} & \multirow{8}{*}{0.5983} \\
\hline Easy to operate & 5.6379 & .610 & .698 & & & & & \\
\hline $\begin{array}{l}\text { Good Internet } \\
\text { access }\end{array}$ & 5.4850 & .693 & .772 & & & & & \\
\hline Smooth & 5.6588 & .778 & .841 & & & & & \\
\hline Highly endurable & 5.6784 & .712 & .788 & & & & & \\
\hline $\begin{array}{l}\text { Many tasks to } \\
\text { finish }\end{array}$ & 5.7438 & .665 & .748 & & & & & \\
\hline Brand reputation & 5.9699 & .653 & .738 & & & & & \\
\hline $\begin{array}{l}\text { Favorable } \\
\text { comments }\end{array}$ & 5.8601 & .707 & .787 & & & & & \\
\hline \multicolumn{9}{|c|}{ Consumers' attitude towards mobile device-based shopping } \\
\hline Positive & 5.3739 & .720 & .818 & \multirow{5}{*}{3.757} & \multirow{5}{*}{75.149} & \multirow{5}{*}{.917} & \multirow{5}{*}{0.9378} & \multirow{5}{*}{0.7512} \\
\hline In favor of & 5.1778 & .837 & .901 & & & & & \\
\hline Meet needs & 5.2275 & .838 & .902 & & & & & \\
\hline $\begin{array}{l}\text { Time-saving, } \\
\text { labor-saving and } \\
\text { economical }\end{array}$ & 5.5673 & .739 & .830 & & & & & \\
\hline Give priority to & 4.9490 & .805 & .879 & & & & & \\
\hline \multicolumn{9}{|c|}{ Consumers' willingness to adopt mobile device-based shopping } \\
\hline Constant adoption & 5.2641 & .761 & .864 & \multirow{3}{*}{3.164} & \multirow{3}{*}{79.096} & \multirow{3}{*}{.911} & \multirow{3}{*}{0.9379} & \multirow{3}{*}{0.7908} \\
\hline Constant attention & 5.3595 & .754 & .859 & & & & & \\
\hline $\begin{array}{l}\text { Recommend } \\
\text { Share }\end{array}$ & $\begin{array}{l}5.1569 \\
5.2105\end{array}$ & $\begin{array}{l}.874 \\
.812\end{array}$ & $\begin{array}{l}.934 \\
.898\end{array}$ & & & & & \\
\hline \multicolumn{9}{|c|}{ Consumers' actual mobile device-based shopping } \\
\hline Frequent adoption & 4.9268 & .853 & .922 & \multirow{4}{*}{3.221} & \multirow{4}{*}{80.527} & \multirow{4}{*}{.919} & \multirow{4}{*}{0.943} & \multirow{4}{*}{0.8054} \\
\hline $\begin{array}{l}\text { Frequent use for } \\
\text { information } \\
\text { collection }\end{array}$ & 5.3072 & .743 & .853 & & & & & \\
\hline All commodities & 5.0039 & .884 & .940 & & & & & \\
\hline One-off purchase & 4.5529 & .776 & .872 & & & & & \\
\hline
\end{tabular}

\subsection{Confirmatory Factor Analysis}

To confirm the efficiency of the measurement dimensions, this study adopts AMOS to make a confirmatory factor analysis (CFA) of the measurement model of seven dimensions, including the information quality of mobile device-based shopping platforms, the system quality of mobile device-based shopping platforms, the service quality of mobile device-based shopping platforms, the quality of mobile devices, consumers' attitude towards mobile device-based shopping, consumers' willingness to adopt mobile device-based shopping, and consumers' actual mobile device-based shopping.

According to Carmines and MacIver (1981), the indicator of the adaptability of model should follow the ideal principle that the ratio of chi-square value to degree of freedom was no higher than 3, RMR (Root mean square residual) and 3, RMR (Root mean square residual) was lower than 0.05, and GFI (Goodness of fit index), AGFI (Adjusted goodness of fit index), NFI (Normed fit index), CFI (Comparative fit index) was over 0.9. (Bagozzi \& Yi, 1988; Joreskog \& Sorbom, 1989) and Sharma (1996) pointed out that a GFI over 0.8 would match its adaptability. Segars and Grover (1993) also argued that an AGFI higher than 0.8 was acceptable. According to the results, the values of the adaptability indicators of the entire measurement model were as follow: $\chi^{2} / \mathrm{df}=$ 2.335; GFI $=0.889 ; \mathrm{AGFI}=0.877 ; \mathrm{NFI}=0.932 ; \mathrm{RFI}=0.920 ; \mathrm{CFI}=0.960 ; \mathrm{RMSEA}=0.042 ; \mathrm{RMR}=0.063$. 
According to this, the values of the adaptability indicators all stayed in the scope of acceptability, so the adaptability of the measurement model of this study was high and the measurement indicators had the architectural validity and measurement efficiency.

\subsection{Comparative Analysis of the Multi-Group Competing Model}

In this study, the 765 retrieved valid copies of questionnaire were differentiated according to the frequency of Internet use and classified according to the average time of Internet use in a day. Those who spending above 4 hours a day were grouped as "frequent", with 285 copies of questionnaire; those spending 2 to 4 hours a day were grouped as "average", with 261 copies of questionnaire; those spending less than 2 hours were grouped as "seldom", with 219 copies of questionnaire.

AMOS was applied to compare the models of the "Frequent", "Average" and "Seldom" groups to find out if the frequency of Internet use had any significant influence on the relationship among the dimensions. The adaptability of the competing model is shown in Table 2. According to the results, $\chi^{2} / \mathrm{df}=1.786 ; \mathrm{RMR}=0.087$; $\mathrm{GFI}=0.806 ; \mathrm{AGFI}=0.763 ; \mathrm{NFI}=0.858 ; \mathrm{RFI}=0.835 ; \mathrm{CFI}=0.931 ; \mathrm{RMSEA}=0.032$. All these values met the requirements on an effective model, so the adaptability of the competing model in this study was high and the model was acceptable. The analysis of the competing model is shown in Table 2:

1. There was a significant difference $(t=-2.531)$ in the influence of information quality of mobile device-based shopping platforms on the path of consumers' attitude towards mobile device-based shopping (H1) between the "Frequent" and "Average" groups. All of the three groups had positive influence, and the influence of the "Average" group was the strongest. This showed that the "Average" group was more likely to accept mobile device-based shopping because of the high information quality of mobile device-based shopping platforms.

2. There was no significant difference in the influence of system quality of mobile device-based shopping platforms on the path of consumers' attitude towards mobile device-based shopping (H2) among the three groups. But according to the influencing coefficient, the "Frequent" group had positive influence, which meant that the group was more likely to accept mobile device-based shopping because of the high system quality of mobile device-based shopping platforms whereas the "Average" and "Seldom" groups had no significant influence.

3. There was a significant difference $(t=-2.121)$ in the influence of service quality of mobile device-based shopping platforms on the path of consumers' attitude towards mobile device-based shopping (H3) between the "Average" and "Seldom" groups. There was also a significant difference $(\mathrm{t}=-2.036)$ between the "Frequent" and "Seldom" groups. A comparison of the influencing coefficient showed that all the three groups had positive influence; the "Seldom" group surpassed the other two in the influence on the path, which indicated that the "Seldom" group paid more attention to the service quality of mobile device-based shopping platforms.

4. There was no significant difference in the influence of the quality of mobile devices on the path of consumers' attitude towards mobile device-based shopping (H4) among the three groups. According to the influencing coefficients, all the three groups had positive influence. This meant that all the three groups were likely to accept mobile device-based shopping because of the high quality of mobile devices.

5. There was no significant difference in the influence of consumers' attitude towards mobile device-based shopping on the path of consumers' willingness to adopt mobile device-based shopping (H5) among the three groups. According to the influencing coefficients, all the three groups had positive influence. This demonstrated that consumers' positive attitude towards mobile device-based shopping would significantly influence consumers' willingness to adopt mobile device-based shopping.

6. There was a significant difference $(t=2.009)$ in the influence of consumers' willingness to adopt mobile device-based shopping on the path of consumers' actual mobile device-based shopping (H6) between the "Average" and "Seldom" groups. A comparison of the influencing coefficient showed that all the three groups had significant positive influence, which reflected that consumers were likely to actually adopt mobile device-based shopping if they had strong willingness to adopt mobile device-based shopping.

According to the above analysis, there were significant differences in four items among the three groups. This showed that the different frequencies of Internet use would have significant difference on the relationship of some paths; hence, $\mathrm{H} 7$ was partially supported. Meanwhile, it demonstrated that different frequencies of Internet use did lead to the difference in relationship structure. This is an important discovery of this study. 
Table 2. Comparative analysis of the multi-group competing model

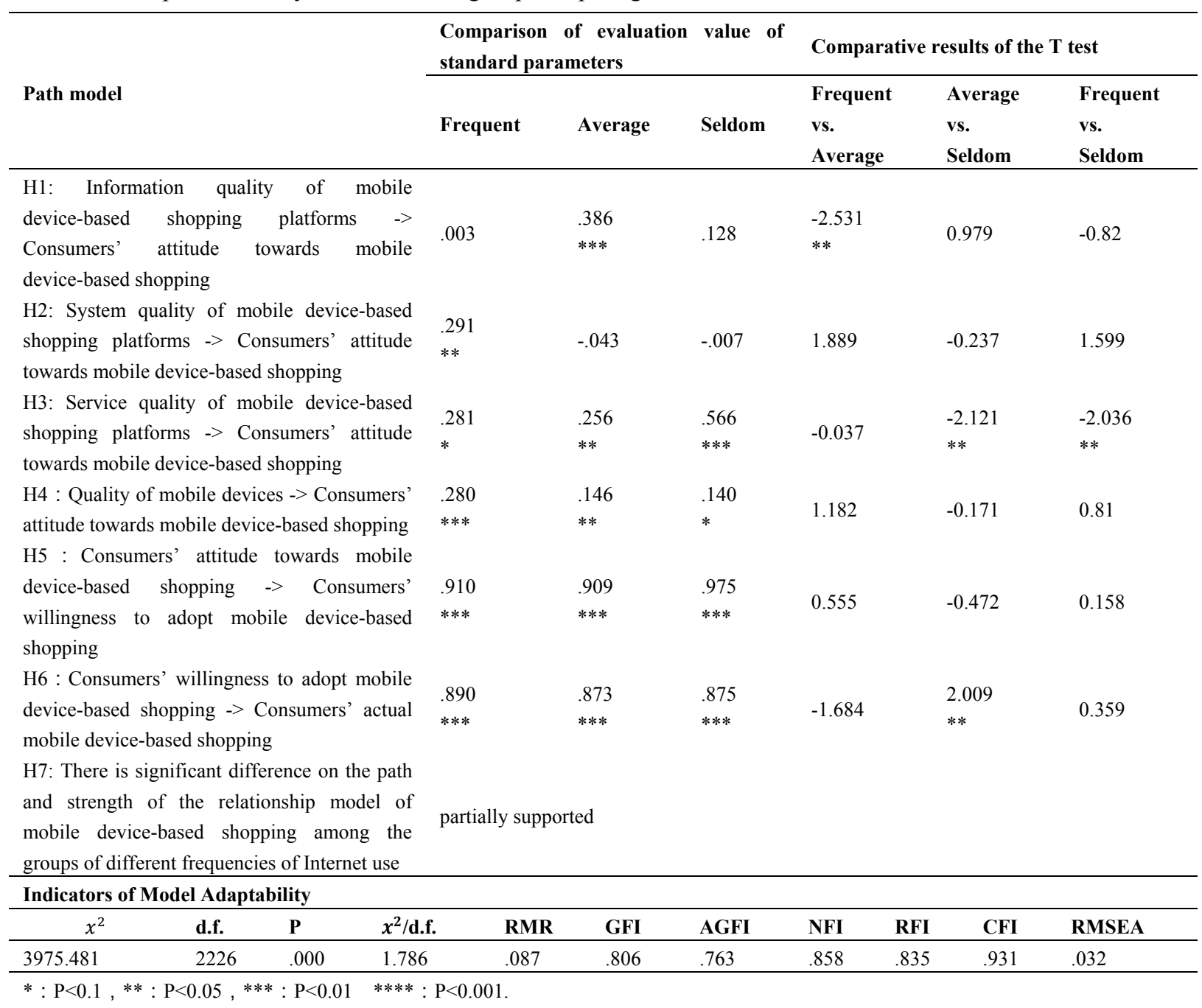

\section{Conclusion and Suggestions}

\subsection{Conclusion and Discussion}

With those who used to adopt tablets or smart phones for mobile device-based shopping as research subjects, this study analyzes the influence of the information quality, system quality, service quality and the quality of mobile devices of mobile device-based shopping platforms on consumers' attitude towards mobile device-based shopping, consumers' willingness to adopt mobile device-based shopping, and consumers' actual adoption of mobile device-based shopping. Meanwhile, this study establishes a relationship model and compares the groups of different frequencies of Internet use. It can provide important architectural concepts and research tools for the academic and industrial circles and is of high academic and practical value. The research results are as follow:

1) As far as the influence of the four variables is concerned, the "Frequent" group showed the greatest influence of the system quality of mobile device-based shopping platforms on consumers' attitude towards mobile device-based shopping. This indicates that the group is more likely to accept mobile device-based shopping because of the high system quality of mobile device-based shopping platforms. However, the "Average" and "Seldom" groups showed no significant influence in the path, which means that the two groups use mobile device-based shopping platforms less frequently than the "Frequent" group and thus they know less about system qualities like system access and system usability.

2) When it comes to the comparison of the influence of the four independent variables, the "Average" group showed the greatest influence of the information quality of mobile device-based shopping platforms on consumers' attitude towards mobile device-based shopping. This indicates that the group is more likely to accept mobile device-based shopping because of the high information quality of mobile device-based 
shopping platforms. Nevertheless, the "Frequent" and "Seldom" groups showed no significant influence in the path. This means that the "Frequent" group may have too high expectation on information quality and the "Seldom" group has little knowledge of information quality; therefore, the two groups have less influence on information quality.

3) According to the comparison of the influence of the influence of the four independent variables, the "Seldom" group showed the greatest influence of the service quality of mobile device-based shopping platforms on consumers' attitude towards mobile device-based shopping. This shows that the group is more likely to accept mobile device-based shopping because of the high service quality of mobile device-based shopping platforms. Also, the "Frequent" and "Seldom" groups showed significant influence in the path, which means that the service quality of mobile device-based shopping platforms is valued by all.

4) All the three groups had positive influence of the quality of mobile devices on consumers' attitude towards mobile device-based shopping, which indicates that they are likely to accept mobile device-based shopping because of the high quality of mobile devices.

5) All the three groups had positive influence of consumers' attitude towards mobile device-based shopping on consumers' willingness to adopt mobile device-based shopping, which indicates that consumers would become willing to adopt mobile device-based shopping if they have a positive attitude towards mobile device-based shopping.

6) All the three groups showed significant influence of the quality of mobile devices on consumers' willingness to adopt mobile device-based shopping on consumers' actual mobile device-based shopping, which indicates that consumers would actually adopt mobile device-based shopping if they have a strong willingness to adopt mobile device-based shopping.

\subsection{Managerial Implications}

According to the comparative analysis of the linear structural model, there are some differences and similarities among groups of different frequencies of Internet use. Therefore, this study proposes the following managerial suggestions:

The "Frequent" group emphasizes the system quality of mobile device-based shopping platforms, so platform suppliers must offer such high system qualities as memory code and products in previous browsing which are adaptive, usable and reliable and have response time (efficiency) and ease of use (convenience). However, the provision of complete system qualities are likely to cause the problem of the disclosure of the personal information about consumers; hence, it is necessary to equip high system quality with perfect supporting facilities (website encoding) and reduce the anxiety of consumers so as to enhance the "Frequent" group's willingness to adopt mobile device-based shopping and actual adoption.

The "Average" group focuses on the information quality of mobile device-based shopping platforms. Most of the people in this group seek information and handle office tasks on the Internet (Taiwan Network Information Center, 2014), so platform suppliers must provide the services featuring fast access to rich information (price comparison or multiple selection) to achieve a complete, understandable, personalized, relevant and secure platform, so that the group would have a positive attitude towards mobile device-based shopping and then develop the willingness to adopt mobile device-based shopping.

The "Seldom" group does not use the Internet unless it is necessary. With little knowledge of how to use Internet-based products, most of the people in the group choose to shop in real stores (Taiwan Network Information Center, 2014). It has been shown that the group expects such high service qualities as "leaving no question" and "fast response", which is consistent with the results of this study. For that reason, platform suppliers must offer high service quality (online Q\&A and fast response) and lead the "Seldom" group to gradually adopt mobile device-based shopping and provide more preferential, so that the group will recognize the advantages of the mobile device-based shopping.

Mobile device manufacturers must create the mobile devices that are easy to understand and operate, so as to eradicate the notion that mobile devices are complicated to use. By doing so, consumers will become more willing to adopt mobile device-based shopping and then put it into practice.

All the three groups showed significant positive influence on the two paths - "the consumers' attitude towards mobile device-based shopping influences their willingness to adopt mobile device-based shopping" and "consumers' willingness to adopt mobile device-based shopping influences consumers actual adoption of mobile device-based shopping". This indicates that different strategies or new functions should be created for different groups. A positioning and mobile marketing system can be established to arouse consumers' positive attitude 
towards mobile device-based shopping, so as to enhancing their willingness to adopt it and actually do it.

\subsection{Research Limitations and Future Studies}

In this study, the consumers who are 20 years old or more and have used tablets or smart phones for mobile device-based shopping are taken as the research subjects. However, the consumers who have an access to mobile device-based shopping platforms are not confined to Taiwan, and the consumers in other countries may be different from those in Taiwan. Hence, it is suggested to expand the research scope in the future to demonstrate the adaptability of the conceptual model.

Additionally, there may be difference in the understanding of and emphasis on mobile device-based shopping among consumers because of the increasingly innovative and diverse mobile devices. Therefore, it is suggested to add more mobile devices for comparative analysis in the future, so that the difference of the relationship model of this study will be shown in different mobile devices, which will increase the research value.

\section{References}

Ajzen, I. (1985). From intentions to actions: A theory of planned behavior, action-control: From cognition to behavior. Baden-Württemberg, Heidelberg: Springer.

Ajzen, I. (1989). Attitude structure and behavior. Hillsdale, NJ: Lawrence Erlbaum Associates.

Angelova, B., \& Zekiri, J. (2011). Measuring customer satisfaction with service quality using American Customer Satisfaction Model (ACSI Model). International Journal of Academic Research in Business and Social Sciences, 1(3), 232-258.

Badlani, M., Motwani, R. K., \& Paryani, P. (2014). Relationship marketing for building long term customer satisfaction in banking industry. Asian Journal of Business and Management, 2(5), 491-497.

Bagozzi, R. P., \& Yi, Y. (1988). On the evaluation of structure equations models. Journal of the Academy of Marketing Science, 16(1), 74-94. http://dx.doi.org/10.1007/BF02723327

Boulding, W., Kalra, A., \& Staelin, R., \& Zeithaml, V. A. (1993). A dynamic process model of service quality: from expectations to behavioral intentions. Journal of Marketing Research, 30(1), 7-27.

Brown, J. J., \& Reingen, P. H. (1987). Social ties and world-of-mouse referral behavior. Journal of Consumer Research, 14(12), 350-362. http://dx.doi.org/10.1086/209118

Browne, M. W., \& Cudeck, R. (1993). Alternative ways of assessing model fit. In K. A. Bollen \& J. S. Long (Eds.), Testing Structural Equation Models (pp. 136-162). Beverly Hills, CA: Sage. http://dx.doi.org/10.1177/0049124192021002005

Brucks, M., \& Zeithaml, V. A. (1991). Price and brand name as indicators of quality dimension. University of Cambridge, England.

Cannière, M. H. D., Pelsmacker, P. D., \& Geuens, M. (2009). Relationship quality and the theory of planned behavior models of behavioral intentions and purchase behavior. Journal of Business Research, 62(1), 82-92. http://dx.doi.org/10.1016/j.jbusres.2008.01.001

Carmines, E. G., \& McIver, J. P. (1981). Analyzing models with unobserved variables: Analysis of covariance structures. In G. W. Bohrnstedt \& E. F. Borgatta (Eds.), Social measurement: Current issues (pp. 65-115). Beverly Hills, Calif: Sage.

Caverly, D. C. (2003). Techtalk: How technology has changed developmental education. Journal of Developmental Education, 27, 38-39.

Chaudhuri, A., \& Holbrook, M. B. (2001). The chain of effects from brand trust and brand affect to brand performance: the role of loyalty. Journal of Marketing, 65(4), 81-93. http://dx.doi.org/10.1509/jmkg.65.2.81.18255

Covaleski, J. (1997). Panel: Internet marketing may reduce prices. Best's Review P/C, 4, 71-72.

D'Ambra, J., \& Rice, R. E. (2001). Emerging factors in user evaluation of the world wide web. Information and Management, 38(6), 373-384. http://dx.doi.org/10.1016/S0378-7206(00)00077-X

Darian, J. C. (1987). In-home shopping: Are there consumer segments? Journal of Retailing, 63(Summer), 163-186.

Davis, F. D., Bagozzi, R. P., \& Warshaw, P. R. (1989). User acceptance of computer technology: A comparison of two theoretical models. Management Science, 35, 982-1003. http://dx.doi.org/10.1287/mnsc.35.8.982 
Delone, W. H., \& Mclean, E. R. (1992). Information system success: The quest for the dependent variable. Information System Research, 3(1), 60-95. http://dx.doi.org/10.1287/isre.3.1.60

Delone, W. H., \& Mclean, E. R. (2003). The delone and mclean of information system success: A ten-year update. Journal of Management Information System, 19(4), 9-30.

Dzewaltowski, D. A., Noble, J. M., \& Shaw, J. M. (1990). Physical activity participation: Social cognitive theory versus the theory of reasoned action and planned behavior. Journal of Sport and Exercise Psychology, 11, 252-269.

Engel, J. F., Blackwell, R. D., \& Miniard, P. W. (1990). Consumer behavior. Fort Worth: Saunders College Publishing.

Fishbein, M., \& Ajzen, I. (1980). Understanding attitudes and predicting social behavior. New Jersey: Prentice-Hall.

Fornell, C. R., \& Larcker, F. F. (1981). Structural equation models with unobservable variables and measurement error. Journal of Marketing Research, 18, 39-51.

Forza, C., \& Filippini, R. (1998). TQM impact on quality conformance and customer satisfaction: A causal model. International Journal of Production Economics, 55(1), 1-20. http://dx.doi.org/10.1016/s0925-5273(98)00007-3

Garvin, D. A. (1987). Competing on the eight dimensions of quality. Harvard Business Review, 65(11), 101-109. http://dx.doi.org/10.1037/0003-066X.45.2.95

Gaski, J. F., \& Nevin, J. R. (1985). The differential effects of exercised and unexercised power sources in a marketing channel. Journal of Marketing Research, 22(2), 130-142.

Gong, J., \& Tarasewich, P. (2004). Guidelines for handheld mobile device interface design. 2004 DSI Annual Meeting (pp. 3751-3756). In Proceedings of the 2004 DSI Annual Meeting.

Hair, J. F., Tatham, R. L., Anderson, R. E., \& Black, W. (2006). Multivariate data analysis (4th ed.). New Jersey: Prentice Hall.

Henry, H., \& Assael, H. (1992). Consumer behavior and marketing action (4th ed.). Boston, PWS: Kent Publishing Company.

Henry, H., \& Assael, H. (1998). Consumer behavior and marketing action (6th ed.). Cincinnati, Ohio: South-Western College Publishing. http://dx.doi.org/10.2307/1250440

Joreskog, K. G., \& Sorbom, D. (1989). LISREL 7 user's reference guide. Chicago: Scientific Software Inc. http://dx.doi.org/10.1177/0146621603027003001

Kaiser, H. F. (1958). The varimax criterion for analysis rotation in factor analysis. Psychometrika, 23(3), 187-200. http://dx.doi.org/10.1007/BF02289233

Kerlinger, F. N. (1978). Foundation of behavioral research. New York: McGraw-Hill.

Lin, C. C., \& Lu, H. (2000). Towards an understanding of the behavioral intention to use a web site. International Journal of Information Management, 20, 197-208.

Morwitz, V. G., \& Schmittlein, D. (1992). Using segmentation to improve sales forecasts based on purchase intent: which intenders actually buy? Journal of Marketing Research, 29(4), 391-405. http://dx.doi.org/10.2307/3172706

Nunnally, J. C. (1978). Psychometric theory. New York: McGraw-Hill.

Parasuraman, A., Zeithaml, V. A., \& Berry, L. L. (1988). Servqual: A multiple-item scale for measuring consumer perceptions of service quality. Journal of Retailing, 64(1), 12-40.

Parasurman, A., Zeithaml, V. A., \& Berry, L. L. (1985). A conceptual model of service and its implications for future research. Journal of Marketing, 49(4), 41-50. http://dx.doi.org/10.2307/1251430

Pitt, L. F., Watson, R. T., \& Kavan, B. C. (1998). Measuring information systems service quality: Lessons from two longitudinal case studies. MIS Quarterly, 5, 61-79.

Robertson, T. S., Zielinski, J., \& Ward, S. (1984). Consumer behaviour. Glenview, Illinois: Scott.

Rosenberg, M. J., \& Hanland, J. C. (1960). Low-commitment consumer behavior. Journal of Abnormal and Social Psychology, 2, 367-372. 
Schiffman, L., \& Kanuk, L. (2004). Consumer behavior. New Jersey: Prentice-Hall.

Seppälä, P., \& Alamaki, H. (2003). Mobile learning in teacher training. Journal of Computer Assisted Learning, 19, 330-335.

Sharma, S. (1996). Applied multivariate techniques (1st ed.). New York: Wiley.

Spears, N., \& Singh, S. N. (2004). Measuring attitude toward the brand and purchase intentions. Journal of Current Issues and Research in Advertising, 26(2), 53-66. http://dx.doi.org/10.1080/10641734.2004.10505164

Williamson, O. E. (1979). Transaction-cost economics: The governance of contractual relations. Journal of Law and Economics, 22(10), 233-261. http://dx.doi.org/10.1086/466942

Zeithaml, V. A., Berry, L. L., \& Parasuraman, A. (1996). The behavioral consequences of service quality. Journal of Marketing, 4, 31-46. http://dx.doi.org/10.2307/1251929

\section{Copyrights}

Copyright for this article is retained by the author(s), with first publication rights granted to the journal.

This is an open-access article distributed under the terms and conditions of the Creative Commons Attribution license (http://creativecommons.org/licenses/by/3.0/). 